gymnospermic ancestors through the Gnetales, as the author himself maintains.

These conclusions have been based upon observations, admirably extensive, but along organographical lines only, and they have been opposed, in review, on that ground. It is therefore worth while directing attention to supporting evidence from an entirely different side.

The long-neglected Maüle reaction ${ }^{2}$ consists in the chlorination of lignin by treatment with potassium permanganate and strong hydrocbloric acid (the original procedure) or directly with chlorine water, followed by ammonia, which may be replaced by an alkali or an organic base. The result is a bright red colour of unknown chemical nature which appears to be an indicator, colourless in the acid form and with red salts, with a $\mathrm{C}=\mathrm{O}$ chromophore group in the molecule.

This reaction was claimed by Maüle as specific for Angiosperm wood, and an extensive test by us in 1932-33, covering forty-three families of Angiosperms, supports this claim, with the outstanding exception that the colour is also given by the wood of all three genera of Gnetales and by them alone among nonAngiosperms, except in the sclerenchyma (not the xylem) of two species of Stangeria and possibly also one species of Podocarpus, which gives a weak reaction according to Crocker ${ }^{3}$.

The Gnetales stand out conspicuously in sharing this distinctively angiospermic element of constitution.

University College, R. C. McLifan. Cardiff. Nov. 5.

${ }^{1}$ Hagerup, "Zur Abstammung einiger Angiospermen durch Gnetales und Coniferae". Copenhagen, 1934.

${ }^{2}$ Maüle, Bei. Wiss. Bot., 4, 166; 1901.

${ }^{3}$ Crocker, Bot. Gaz., 95, 168; 1933.

\section{Traffic Noise}

Now that so much is being done in order to find means of reducing street and other noises, it may be worth while considering whether there are not more factors than intensity and character of the noise to be taken into account. It is fairly probable that any noise is more objectionable when it is intermittent ; and it is also possible that an intermittent noise with quick rate of change is more objectionable than one in which the rate is slow.

Sir Herbert Maxwell points out in NaTuRE of November 3 that horse traffic used to be more noisy than the present-day motors; but it certainly caused less annoyance. May not the reason, or one of the reasons, be that changing gear or using a cut-out involves sudden change in noise; and may not the greater speed of modern traffic be a contributing cause of the trouble, in that fast approach of a noisy vehicle results in greater rate of change of noise as heard by anyone at a standstill? The clatter of a two-horse dray rumbling over granite setts was continuous, and became audible gradually to anyone who was not on the move; but the noises created by a motor cycle without silencer, or by a bus changing gear after getting under way involve quick rate of change. I am sure that rate of change must be taken into account in deciding whether a given noise is objectionable or not.
4, Dean's Yard, P. J. H. UNNA.
London, S.W.1. Nov. 23.

\section{Corrections to the Refractive Indices of Quartz in the Infra-Red}

IN the region 3-4 $\mu$, the dispersive power of crystalline quartz (ordinary ray) is about four times that of fluorite and thirteen to fourteen times that of rocksalt, but, because of strong absorption beyond $3.6 \mu$ and also between $2 \cdot 8 \mu$ and $3 \cdot 1 \mu$, quartz has been neglected as a prism material in this part of the spectrum. The high dispersive power does, nevertheless, more than compensate for the loss due to absorption, and better resolution is obtainable than with fluorite.

When prisms of quartz and fluorite were used in a recent research, it was found that wave-length discrepancies occurred between the results obtained with the two prisms, and these were traceable to the relatively inaccurate data for the refractive indices of quartz. The figures available for quartz in this region are due to Rubens ${ }^{1}$, who measured the refractive indices of both quartz and fluorite by the method of coincidences, using a wire grating ; later he corrected his results to be in accordance with Paschen's more accurate values for fluorite ${ }^{2}$. Paschen ${ }^{3}$ has since given still more accurate data for fluorite, and Rubens' values for quartz are no longer correlated with these. Moreover, the dispersion curve for quartz up to $3 \mu$ is accurately known ${ }^{4}$ and is smooth, while Rubens' curve, in addition to showing two rather abrupt bends, does not join up well with this but intersects it at a small angle at $3 \mu$.

From the comparison of the results lately obtained with quartz and fluorite prisms, values for the refractive indices of quartz have been estimated for several wave-lengths between $3 \mu$ and $3 \cdot 8 \mu$, and these, when plotted, are found to lie on a smooth continuation of the curve up to $3 \mu$. These corrected refractive indices of quartz are given in the accompanying table, and should be regarded as provisional values, suitable for adoption until direct determinations of greater accuracy become available, whilst not in any way obviating the need for the latter. The corrections proposed, it will be seen, are of quite appreciable magnitude.

\begin{tabular}{|c|c|c|r|}
\hline$\lambda$ & $n$ (Rubens) & $n$ (Corrected) & Difference \\
\cline { 1 - 2 } $3.03 \mu$ & 1.4987 & 1.4987 & 0 \\
3.18 & 1.4944 & 1.4947 & +0.0003 \\
3.40 & 1.4879 & 1.4885 & +0.0006 \\
3.63 & 1.4799 & 1.4809 & +0.0010 \\
3.80 & 1.4740 & 1.4746 & +0.0006 \\
3.87 & $(1.4715)^{*}$ & 1.4715 & 0 \\
\hline
\end{tabular}

* Interpolated value.

Physics Department,

D. G. Drummond.

Armstrong College,

Newcastle-on-Tyne.

1 Rubens, Ann. Phys., 53, 273 ; 1894.

${ }^{2}$ Paschen, Ann. Phys., 53, 325; 1894.

3 Paschen, Ann. Phys., 4, 299; '1901. 41, 670; 1913.

Paschen, Ann. Phys., 35, 1005 ; 1911. Carvallo, C.R., 126, 728; 1898. Coblentz, Sci. Pap. Bur. Stan., 16, 701 ; 1920.

\section{Spectrum of Acrolein}

IN connexion with measurements on the photochemical decomposition of acrolein we have measured (Hilger E 315 spectrograph) its ultra-violet absorption spectrum. There are two distinct regions of absorption, one consisting of bands with no overlapping continuum, extending from c. $4000 \mathrm{~A}$. to $2800 \mathrm{~A}$. ; the other of continuous absorption beginning at 